\title{
Sex Influences the Effect of a Lifelong Increase in Serotonin Transporter Function on Cerebral Metabolism
}

\author{
Neil Dawson, ${ }^{1 \star}$ Linda Ferrington, ${ }^{2}$ Henry J. Olverman, ${ }^{1}$ Anthony J. Harmar, ${ }^{3}$ and \\ Paul A. T. Kelly ${ }^{1}$ \\ ${ }^{1}$ Centres for Cognitive and Neural Systems, University of Edinburgh, Scotland \\ ${ }^{2}$ Neuroscience Research, University of Edinburgh, Scotland \\ ${ }^{3}$ Centre for Cardiovascular Sciences, School of Biomedical Sciences, University of Edinburgh, Scotland
}

Polymorphic variation in the human serotonin transporter (SERT; 5-HTT) gene resulting in a lifelong increase in SERT expression is associated with reduced anxiety and a reduced risk of affective disorder. Evidence also suggests that sex influences the effect of this polymorphism on affective functioning. Here we use novel transgenic mice overexpressing human SERT ( $h$ SERT OVR) to investigate the possible influence of sex on the alterations in SERT protein expression and cerebral function that occur in response to increased SERT gene transcription. SERT binding levels were significantly increased in the brain of $h$ SERT OVR mice in a region-dependent manner. The increased SERT binding in $h$ SERT OVR mice was more pronounced in female than in male mice. Cerebral metabolism, as reflected by a quantitative index of local cerebral glucose utilization (iLCMRglu), was significantly decreased in many brain regions in $h$ SERT OVR female as compared with wild-type female mice, whereas there was no evidence for a significant effect in any region in males. The ability of $h$ SERT overexpression to modify cerebral metabolism was significantly greater in females than in males. This effect was particularly pronounced in the medial striatum, globus pallidus, somatosensory cortex, mamillary body, and ventrolateral thalamus. Overall, these findings demonstrate that the influence of a lifelong increase in SERT gene transcription on cerebral function is greater in females than in males and may relate, in part, to the influence of sex on genetically driven increases in SERT protein expression. (c) 2009 Wiley-Liss, Inc.

Key words: mice; anxiety; 2-deoxyglucose; transgenic

5-Hydroxytryptamine (5-HT; serotonin) is implicated in the regulation of emotion and in the etiology of affective disorders. The serotonin transporter (SERT; 5$\mathrm{HTT}$ ) regulates 5 -HT availability through reuptake of the neurotransmitter into the presynaptic terminal. A number of polymorphisms in the human SERT gene (SLC6A4; hSERT) have been found to regulate SERT protein expression and function. One such polymor- phism, a 44-bp insertion/deletion (the "long" [1] and "short" [s] allele, respectively) in the promoter (5HTTLPR) region of the gene results in differential levels of SERT expression. Cells expressing two copies of the "l" allele show increased SERT mRNA levels and a 2fold increase in 5-HT uptake when compared with those with one or two copies of the "s" allele (Lesch et al., 1996). Human individuals homozygous for the "l" allele also display increased SERT mRNA, binding sites, and 5-HT reuptake when compared to "s" allele homozygotes (Hanna et al., 1998; Little et al., 1998; Greenberg et al., 1999; Heinz et al., 2000). Interestingly, individuals homozygous for the "l" allele also exhibit decreased anxiety (Lesch et al., 1996; Greenberg et al., 2000; Schinka et al., 2004) and are less likely to experience depression (Furlong et al., 1998; Mann et al., 2000; Lotrich and Pollock, 2004; Caspi et al., 2003) than those homozygous for the "s" allele.

Evidence suggests that sex modulates the influence of this polymorphism on affective functioning, although there is inconsistency between studies. In females, the "s" allele has been reported to increase the risk of depressive symptomology (Brummett et al., 2008; Grabe et al., 2005; Sjoberg et al., 2006), while no such effect was found in males. In contrast, several studies report the opposite (Du et al., 2000; Mizuno et al., 2006) or no (Ball et al., 1997; Gelernter et al., 1998; Greenberg et al., 2000) sex effect. Data from transgenic animal studies are more consistent, where genetically determined

Contract grant sponsor: European Commission Research Directorates, Research and Technological Development Project, 6th Framework Programme; Contract grant number: LSHM-CT-2003-503474.

$\star$ Correspondence to: Neil Dawson, Centre for Cognitive and Neural Systems, School of Biomedical Sciences, University of Edinburgh, 1 George Square, Edinburgh, EH8 9JZ, Scotland.

E-mail: N.dawson@ed.ac.uk

Received 12 November 2008; Revised 19 January 2009; Accepted 21 January 2009

Published online 26 March 2009 in Wiley InterScience (www. interscience.wiley.com). DOI: 10.1002/jnr.22062 
alterations in SERT expression produce a greater effect in females. For example, in SERT knockout mice (SERT KO), the resulting alterations in anxiety-like behavior (Holmes et al., 2003) and serotonin system functioning ( $\mathrm{Li}$ et al., 2000; Kim et al., 2005) are more pronounced in females. However, it could be argued that the sex effects found in SERT KO mice, where SERT function is completely abolished, may be more pronounced than those in response to more subtle, naturally occurring variations in SERT function, such as those found in humans.

Recently, a novel mouse has been genetically engineered to overexpress $h$ SERT ( $h$ SERT OVR), resulting in an approximate 2-fold increase in SERT protein expression (Loder et al., 2000; Jennings et al., 2006). This animal model allows for the investigation of the possible modulatory influence of sex on the phenotypic and endophenotypic outcomes of a subtle alteration in SERT protein expression. In the present study, we investigate whether sex influences the increase in SERT protein expression found in the brain of hSERT OVR mice. Furthermore, we examined constitutive cerebral metabolism in hSERT OVR mice, as reflected by an quantitative index of local cerebral glucose utilization (iLCMRglu, Dawson et al., 2008), and we also determine whether the modification of cerebral metabolism by a lifelong increase in SERT expression is influenced by sex.

\section{MATERIALS AND METHODS}

\section{Animals}

All experiments were subject to local ethical review and were conducted in accordance with the UK Animals (Scientific Procedures) Act (1986) and European Communities Directive 86/609. A colony of $h$ SERT OVR mice was generated as previously described (Loder et al., 2000; Jennings et al., 2003), and all experiments included both male and female heterozygous transgenic ( $h$ SERT OVR) mice and their wild-type littermates (CBAxC57BL/6J background, aged 24 months). Animals were group housed (5-6 animals per cage) under strict environmental conditions with a 12-hr light-dark cycle (lights on 0700) and a room temperature of $21^{\circ} \mathrm{C} \pm$ $1^{\circ} \mathrm{C}$. Food and water were available ad libitum until the night before the experiment, at which point access to food was restricted overnight (12 hr before experimental manipulation) for animals involved in the 2-deoxyglucose imaging study to obviate any possible hyperglycemia during the experimental procedure. At approximately 3 weeks before the start of the experiments, and again at 1 week, vaginal smears were taken and assessed by trained animal technicians, and the mice were found to be cycling synchronously with an estrus cycle of 4 days. Thus, tissue collection for the paroxetine binding study and in the determination of iLCMRglu was spread across 4 consecutive days in order to control for the possible influence of the estrus cycle in females on these parameters. Within each group $(n=6)$, no one day of the estrus cycle was represented in any more than two mice.

\section{Measurement of SERT Binding Sites}

Brains from $h$ SERT OVR mice (male $n=6$, female $n=6$ ) and their wild-type littermates (male $n=6$, female $n=6$ ) were rapidly dissected out and frozen in isopentane at $-40^{\circ} \mathrm{C}$ and stored at $-80^{\circ} \mathrm{C}$ before sectioning. Coronal sections $(20 \mu \mathrm{m})$ were cut in a cryostat $\left(-20^{\circ} \mathrm{C}\right)$ and thawmounted onto poly-L-lysine-coated slides (VWR, UK). Two consecutive sections were mounted onto separate slides for the duplicate determination of total binding, and a third adjacent section was mounted onto a separate slide for the assessment of nonspecific binding. Sections were allowed to dry at room temperature before being stored at $-80^{\circ} \mathrm{C}$ until the day of the experiment.

On the day of the experiment, tissue sections were removed from the freezer and allowed to equilibrate to room temperature for $30 \mathrm{~min}$. Slides were preincubated in $50 \mathrm{mM}$

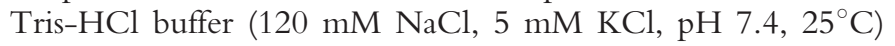
for $2 \times 5 \mathrm{~min}$. For the determination of total binding, sections were incubated in the same buffer described above but containing $0.25 \mathrm{nM}\left[{ }^{3} \mathrm{H}\right]$ paroxetine (Amersham Bioscience, UK, specific activity $19.1 \mathrm{Ci} / \mathrm{mM})$ for $2 \mathrm{hr}\left(25^{\circ} \mathrm{C}\right)$. Nonspecific binding was determined by exposing sections to the same incubation conditions in the presence of $4 \mu \mathrm{M}$ citalopram (Sigma-Aldrich, UK). Sections were then washed in $50 \mathrm{mM}$ Tris-HCl buffer $(4 \times 30 \mathrm{~min})$ at $4^{\circ} \mathrm{C}$ before being dipped in ice-cold distilled water and rapidly dried under a stream of cold air.

Slides were apposed to X-ray film (Kodak, SB-5) for 6 weeks at $-40^{\circ} \mathrm{C}$ along with a set of precalibrated tritium standards $\left(\left[{ }^{3} \mathrm{H}\right]\right.$ microscales, $0.07-33.6 \mathrm{nCi} / \mathrm{mg}$ tissue equivalents, Amersham International, UK) and films were developed in accordance with the manufacturer's instructions. Autoradiographic images on x-ray film were analyzed by a computerbased image analysis system (MCID, Imaging Research Inc.). The tissue-equivalent $\left[{ }^{3} \mathrm{H}\right]$ concentration of each brain region of interest (RoI) was calculated from the mean optical density of six bilateral measurements, and the optical density- $-\left[{ }^{3} \mathrm{H}\right] \mathrm{cal}-$ ibration curve was generated from the coexposed standards. The concentration of $\left[{ }^{3} \mathrm{H}\right]$ paroxetine bound to SERT in each brain region was then calculated by subtracting the value of nonspecific binding from the mean total binding (determined from duplicate measurement) with reference to the specific activity $(19.1 \mathrm{Ci} / \mathrm{mM})$ of the radioligand. Throughout these studies, there was no evidence of a significant difference in the level of nonspecific binding between either sex or genotype in any RoI. This supports the suggestion that differences found in $\left[{ }^{3} \mathrm{H}\right]$ paroxetine binding between both sex and genotype are due to alterations in the specific binding of this radioligand to SERT.

\section{Measurement of iLCMRglu}

Constitutive iLCMRglu was determined in a total of 23 wild-type (male $n=11$, female $n=12$ ) and 23 hSERT OVR (male $n=11$, female $n=12$ ) conscious mice by the adapted and validated 2-deoxyglucose autoradiographic imaging technique previously developed in this laboratory (Dawson et al., 2008). Mice were injected intraperitoneally with $5 \mu \mathrm{Ci}$ of $\left[{ }^{14} \mathrm{C}\right]$-2-deoxyglucose in $0.4 \mathrm{ml}$ of saline at a steady rate 


$$
\text { iLCMRglu }=\left(\frac{C_{i}^{*}(T)}{\left(C_{p}^{*}(t) / C_{p}(t)\right)}\right)\left(\frac{\left(C_{p}^{*}(t) / C_{p}(t)\right)_{\text {individual }}}{\text { mean }\left(C_{p}^{*}(t) / C_{p}(t)\right)_{\text {group }}}\right)\left(\frac{\text { mean }\left(C_{p}^{*}(t) / C_{p}(t)\right)_{\text {group }}}{\text { mean }\left(\left(C_{p}^{*}(t) / C_{p}(t)\right)_{\text {control group }}\right.}\right)
$$

Fig. 1. Operational equation for the determination of iLCMRglu. $\mathrm{C}_{1}^{\star}(\mathrm{T})$ represents the total $\left[{ }^{14} \mathrm{C}\right]$ present in a single brain region. $\mathrm{C}_{\mathrm{p}}^{\star}(\mathrm{t})$ indicates the concentration of $\left[{ }^{14} \mathrm{C}\right]-2-\mathrm{DG}$, and $\mathrm{C}_{\mathrm{p}}(\mathrm{t})$ indicates the concentration of glucose present in the terminal blood sample. $\left(\mathrm{C}_{\mathrm{p}}^{\star}(\mathrm{t}) / \mathrm{C}_{\mathrm{p}}(\mathrm{t})\right)_{\text {individual }}$ represents the terminal plasma $\left[{ }^{14} \mathrm{C}\right] /[$ glucose $]$

over a $10-\mathrm{sec}$ period before being returned to their home cage. At exactly $45 \mathrm{~min}$ after isotope injection, animals were decapitated and a terminal blood sample collected by torso inversion. The brain was rapidly dissected out intact, frozen in isopentane $\left(-40^{\circ} \mathrm{C}\right)$, and stored at $-80^{\circ} \mathrm{C}$ until sectioning. Blood samples were centrifuged to separate the plasma, and aliquots were removed for the determination of plasma glucose $(10 \mu \mathrm{l})$ and ${ }^{14} \mathrm{C}(20 \mu \mathrm{l})$ concentrations by semiautomated glucose oxidase assay (Beckman Glucose Analyzer) and liquid scintillation analysis (Packard, Tricarb 2900TL), respectively.

Frozen brains were sectioned $(20 \mu \mathrm{m})$ in the coronal plane in a cryostat. A series of three consecutive sections were retained from every $120 \mu \mathrm{m}$, thaw mounted, and rapidly dried on a hot plate $\left(70^{\circ} \mathrm{C}\right)$. Autoradiograms were generated by apposing these sections, together with precalibrated ${ }^{14} \mathrm{C}$-standards (40-1,069 $\mathrm{nCi} / \mathrm{mg}$ tissue equivalents; Amersham International, UK) to X-ray film (Kodak, SB-5) for 7 days. Autoradiographic images were analyzed by a computer-based image analysis system (MCID/M5+). The local isotope concentration for each brain RoI was derived from the optical density (OD) of autoradiographic images relative to that of the coexposed ${ }^{14} \mathrm{C}$ standard. Measurements were taken from 46 anatomically distinct brain regions defined with reference to a stereotactic mouse brain atlas (Franklin and Paxinos, 1997). iLCMRglu was calculated from the ${ }^{14} \mathrm{C}$-isotope concentration in each brain region and the terminal plasma $\left[{ }^{14} \mathrm{C}\right] /$ [glucose] ratio in accordance with the operational equation (Fig. 1) for this methodology. The use of this analytical approach has previously been shown to provide a valid measure of cerebral metabolism (Dawson et al., 2008), which parallels measurements gained by using the originally method outlined by Sokoloff et al. (1977). The experimental procedure applied here is also less invasive and reduces the stress experienced by the animals by avoiding the requirement for both intravascular cannulation and prolonged restraint, which are necessary in the original methodology.

\section{Statistical Analysis}

Data from $\left[{ }^{3} \mathrm{H}\right]$ paroxetine binding and constitutive 2deoxyglucose studies were analyzed by two-way analysis of variance (ANOVA) with sex (male, female) and genotype (wild type, hSERT OVR) as dependent variables. Within both studies, a significant genotype effect was analyzed within sex by two-way ANOVA with Bonferroni post hoc correction for multiple comparisons. In iLCMRglu studies, in keeping with previous studies of similar experimental design, anatomically discrete brain regions were assumed to represent ratio for an individual animal, mean $\left(\mathrm{C}_{\mathrm{p}}^{\star}(\mathrm{t}) / \mathrm{Cp}(\mathrm{t})\right)_{\text {group }}$ represents the mean plasma ratio of the appropriate experimental (treatment) group for the given individual animal, and mean $\left(\mathrm{C}_{\mathrm{p}}^{\star}(\mathrm{t}) / \mathrm{Cp}(\mathrm{t})\right)_{\text {control group }}$ represents the mean plasma ratio of the chosen control group. Adapted from Dawson et al. (2008).

variables that can be analyzed independently within each measure (McCulloch et al., 1982), and no correction was applied for multiple comparisons. In addition, the influence of sex on the ability of hSERT overexpression to alter the global level of cerebral metabolism was analyzed by the Mann-Whitney $U$-test comparison of the difference (ratio) between hSERT OVR and wild-type mice (within sex). Plasma variables for the 2-deoxyglucose study were analyzed by Student's $t$-test with Bonferroni post hoc correction applied for multiple comparisons. Significance was set at $P<0.05$ throughout.

\section{RESULTS}

\section{SERT Binding Sites in Male and Female hSERT OVR Mice}

The distribution and concentration of $\left[{ }^{3} \mathrm{H}\right]$ paroxetine binding in this study was similar to that reported by others in the brains of rats (DeSouza and Kuyatt, 1987; Reader et al., 1998; Sharkey et al., 1991). In all animals, $\left[{ }^{3} \mathrm{H}\right]$ paroxetine binding was highest in the dorsal and median raphé, the molecular layer of the hippocampus, amygdaloid nuclei, hypothalamus, and the substantia nigra. Medium levels of binding were evident in subregions of the hippocampus and the nucleus accumbens, whereas relatively low levels of binding were detected in the striatum and anterior cortical regions [e.g., medial prefrontal cortex (mPFC), anterior cingulate, and frontal cortex].

In the majority of brain regions, $\left[{ }^{3} \mathrm{H}\right]$ paroxetine binding tended to be greater in females than in males. Indeed, $\left[{ }^{3} \mathrm{H}\right]$ paroxetine binding was found to be significantly higher in females compared with males in 19 of the 42 brain regions analyzed. This effect was particularly prevalent in cortical regions (including the dorsal mPFC $+65 \%$, posterior cingulate $+97 \%$, and somatosensory cortex $+46 \%$ ), the hippocampus (including the dentate PO $+53 \%$, CA $2+30 \%$, ventral CA $1+51 \%)$, components of the basal ganglia (medial striatum $+27 \%$, globus pallidus $+70 \%)$ and thalamic regions (mediodorsal $+47 \%$, ventrolateral $+173 \%$ ) (Fig. 2, Table I). In contrast, there was no evidence for a significant sex difference in $\left[{ }^{3} \mathrm{H}\right]$ paroxetine binding in any of the amygdaloid or raphé nuclei.

In both male and female animals, the density of $\left[{ }^{3} \mathrm{H}\right]$ paroxetine binding tended to be greater in hSERT OVR mice compared with wild-type animals in the majority of brain areas. In males, $\left.{ }^{3} \mathrm{H}\right]$ paroxetine binding was significantly increased in hSERT OVR mice in 5 of the 42 brain regions analyzed (Fig. 2, Table I). In 
Dorsal mPFC

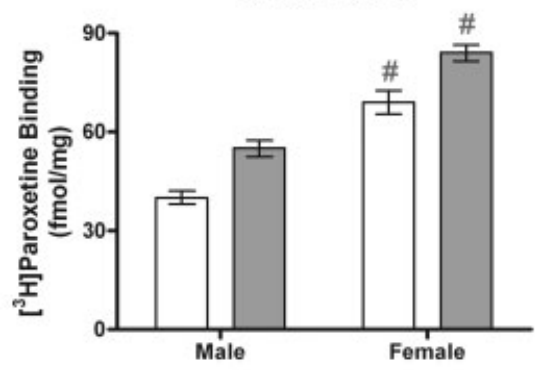

Ventrolateral Thalamus

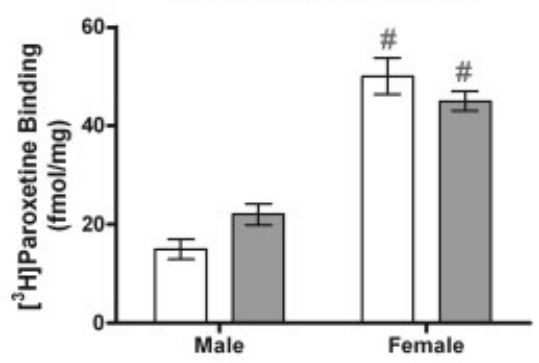

Dorsal Subiculum

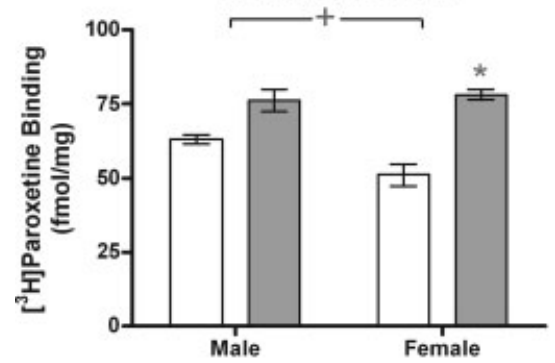

Somatosensory Cortex

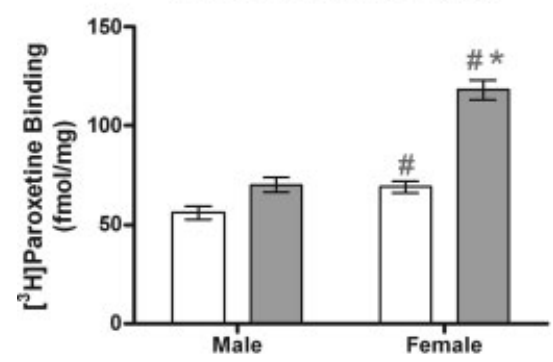

Central Amygdala

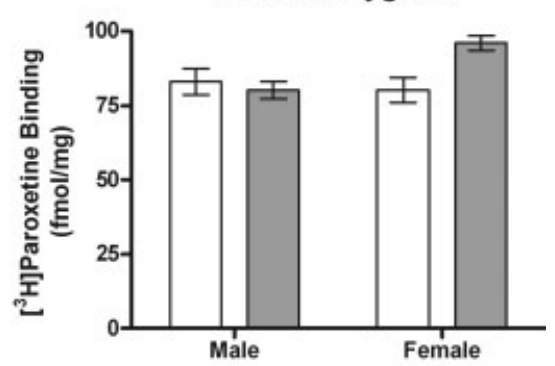

Septal Nucleus

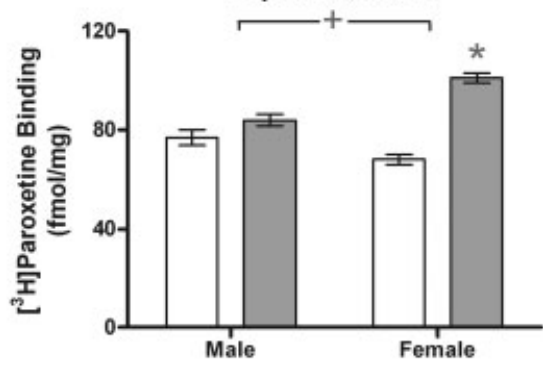

Orbitofrontal Cortex
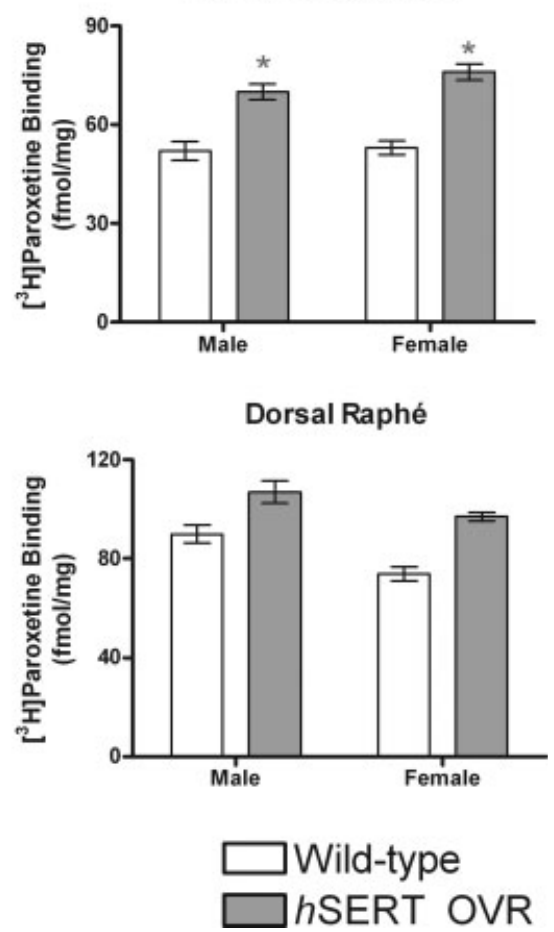

Fig. 2. $\left[{ }^{3} \mathrm{H}\right]$ Paroxetine binding (fmol/ $\mathrm{mg}$ tissue) in eight representative brain regions of wild-type and $h$ SERT OVR male and female mice. Data were analyzed by two-way ANOVA. ${ }^{\star} P<$ 0.05 significant genotype effect (within sex with Bonferroni correction applied). ${ }^{\#} P<0.05$ significant sex effect. ${ }^{+} P<0.05$ significant sex $\times$ genotype interaction. females, significant increases in $\left[{ }^{3} \mathrm{H}\right]$ paroxetine binding in hSERT OVR mice were more widespread, occurring in 12 brain regions. This suggests that sex may modulate the ability of $h$ SERT overexpression to increase SERT protein levels, with a greater effect being observed in females than in males. Indeed, a significant sex $\times$ genotype interaction was found in the septal nucleus $\left(F_{1,32}=\right.$ 4.37, $P<0.05)$ and dorsal subiculum $\left(F_{1,34}=4.85\right.$, $P<0.05)$, where the ability of hSERT overexpression to increase $\left[{ }^{3} \mathrm{H}\right]$ paroxetine binding was significantly more marked in females than in males.

Interestingly, $\left[{ }^{3} \mathrm{H}\right]$ paroxetine binding was not significantly altered in hSERT OVR animals in a number of brain regions, including the piriform cortex $(+8 \%)$ or any of the amygdaloid nuclei (range $-5 \%$ to $+8 \%$ ), indicating that increased SERT protein expression in hSERT OVR mice is regionally heterogenous (Fig. 2, Table I). 
TABLE I. $\left[{ }^{3} \mathrm{H}\right]$ Paroxetine Binding in $h$ SERT OVR and Wild-type Mice

\begin{tabular}{|c|c|c|c|c|c|c|c|c|c|c|c|c|c|c|}
\hline \multirow[b]{3}{*}{ Site } & \multicolumn{7}{|c|}{ Male } & \multicolumn{7}{|c|}{ Female } \\
\hline & \multicolumn{3}{|c|}{ Wild type } & \multicolumn{3}{|c|}{ hSERT OVR } & \multirow{2}{*}{$\begin{array}{c}\% \\
\text { Difference }\end{array}$} & \multicolumn{3}{|c|}{ Wild type } & \multicolumn{3}{|c|}{ hSERT OVR } & \multirow{2}{*}{$\begin{array}{c}\% \\
\text { Difference }\end{array}$} \\
\hline & Mean & & SEM & Mean & & SEM & & Mean & & SEM & Mean & & SEM & \\
\hline \multicolumn{15}{|l|}{ Cortex } \\
\hline Orbitofrontal & 52 & \pm & 7 & 70 & \pm & $6^{\star}$ & 35 & 53 & \pm & 5 & 76 & \pm & $6^{\star}$ & 43 \\
\hline Frontal & 72 & \pm & 9 & 87 & \pm & 6 & 21 & 66 & \pm & 6 & 82 & \pm & 6 & 23 \\
\hline Anterior cingulate & 38 & \pm & 6 & 57 & \pm & 9 & 52 & 50 & \pm & $6^{\#}$ & 81 & \pm & $7^{\#, \star}$ & 60 \\
\hline Dorsal medial prefrontal & 40 & \pm & 5 & 55 & \pm & 6 & 37 & 69 & \pm & $9^{\#}$ & 84 & \pm & $6^{\#}$ & 22 \\
\hline Ventral medial prefrontal & 45 & \pm & 5 & 68 & \pm & $5^{\star}$ & 50 & 73 & \pm & $5^{\#}$ & 83 & \pm & $8^{\#}$ & 13 \\
\hline Somatosensory & 56 & \pm & 8 & 70 & \pm & 9 & 24 & 69 & \pm & $7^{\#}$ & 118 & \pm & $12^{\#, \star}$ & 71 \\
\hline Temporoparietal & 30 & \pm & 8 & 59 & \pm & $7 \star$ & 99 & 53 & \pm & 6 & 78 & \pm & 7 & 45 \\
\hline Posterior cingulate & 18 & $\overline{ \pm}$ & 5 & 34 & \pm & 5 & 94 & 31 & $\overline{ \pm}$ & $6^{\#}$ & 75 & \pm & $9^{\#, \star}$ & 140 \\
\hline Piriform & 88 & \pm & 9 & 101 & \pm & 11 & 14 & 84 & \pm & 12 & 86 & \pm & 12 & 2 \\
\hline Entorhinal & 87 & \pm & 9 & 88 & \pm & 10 & 2 & 72 & \pm & 4 & 96 & \pm & 8 & 33 \\
\hline \multicolumn{15}{|l|}{ Basal ganglia } \\
\hline Medial striatum & 47 & \pm & 6 & 63 & \pm & 6 & 34 & 55 & \pm & $6^{\#}$ & 87 & \pm & $9^{\#, \star}$ & 59 \\
\hline Lateral striatum & 34 & \pm & 7 & 47 & \pm & 9 & 37 & 36 & \pm & $5^{\#}$ & 68 & \pm & $6^{\#, \star}$ & 85 \\
\hline Globus pallidus & 35 & \pm & 6 & 58 & \pm & $7 \star$ & 66 & 74 & $\begin{array}{l}\dot{-} \\
\pm\end{array}$ & $4^{\#}$ & 86 & \pm & $9^{\#}$ & 17 \\
\hline Subthalamic nucleus & 42 & \pm & 6 & 45 & \pm & 9 & 7 & 37 & \pm & 5 & 32 & \pm & 5 & -13 \\
\hline Substantia nigra pars reticulata & 88 & \pm & 5 & 102 & \pm & 9 & 16 & 113 & \pm & $11^{\#}$ & 120 & \pm & $12^{\#}$ & 7 \\
\hline Substantia nigra pars compacta & 74 & \pm & 6 & 91 & \pm & 7 & 22 & 90 & \pm & 4 & 113 & \pm & 12 & 25 \\
\hline \multicolumn{15}{|l|}{ Amygdala } \\
\hline Medial & 86 & \pm & 12 & 82 & \pm & 7 & -5 & 91 & \pm & 13 & 103 & \pm & 9 & 13 \\
\hline Basolateral & 87 & \pm & 12 & 83 & \pm & 7 & -4 & 99 & \pm & 11 & 92 & \pm & 7 & -7 \\
\hline Central & 83 & \pm & 11 & 80 & \pm & 7 & -4 & 80 & \pm & 10 & 96 & \pm & 6 & 20 \\
\hline \multicolumn{15}{|l|}{ Thalamic nuclei } \\
\hline Anterior & 56 & \pm & 5 & 61 & \pm & 6 & 11 & 59 & \pm & 8 & 76 & \pm & $7 \star$ & 28 \\
\hline Mediodorsal & 43 & \pm & 7 & 51 & \pm & 4 & 21 & 56 & \pm & $7^{\#}$ & 84 & \pm & $9^{\#, \star}$ & 51 \\
\hline Ventrolateral & 15 & \pm & 5 & 22 & \pm & 5 & 5 & 50 & \pm & $9^{\#}$ & 45 & \pm & $5^{\#}$ & -10 \\
\hline \multicolumn{15}{|l|}{ Hypothalamic nuclei } \\
\hline Anterior & 81 & \pm & 8 & 88 & \pm & 5 & 8 & 93 & \pm & $8^{\#}$ & 114 & \pm & $11^{\#}$ & 21 \\
\hline Ventrolateral & 69 & \pm & 7 & 84 & \pm & 5 & 21 & 84 & \pm & 9 & 101 & \pm & 16 & 19 \\
\hline \multicolumn{15}{|l|}{ Hippocampal } \\
\hline Molecular layer & 103 & \pm & 6 & 101 & \pm & 7 & -2 & 103 & \pm & 13 & 105 & \pm & 7 & 2 \\
\hline Dorsal subiculum & 63 & \pm & 4 & 76 & \pm & 9 & 20 & 56 & \pm & 9 & 78 & \pm & $4 \star^{+}+$ & 40 \\
\hline Dentate PO & 22 & \pm & 7 & 36 & \pm & 6 & 58 & 38 & $\overline{ \pm}$ & $3^{\#}$ & 48 & \pm & $6^{\#}$ & 27 \\
\hline Dorsal CA1 & 48 & \pm & 6 & 61 & \pm & 5 & 27 & 61 & \pm & $5^{\#}$ & 80 & \pm & $4^{\#, \star}$ & 31 \\
\hline CA2 & 66 & \pm & 6 & 70 & \pm & 6 & 5 & 85 & $\begin{array}{l}\overline{ \pm} \\
\pm\end{array}$ & $8^{\#}$ & 92 & \pm & $8^{\#}$ & 8 \\
\hline Ventral CA1 & 63 & \pm & 8 & 67 & \pm & 5 & 6 & 92 & $\overline{ \pm}$ & $8^{\#}$ & 104 & \pm & $8^{\#}$ & 13 \\
\hline Ventral subiculum & 79 & \pm & 7 & 89 & \pm & 7 & 13 & 90 & \pm & 9 & 96 & \pm & 8 & 6 \\
\hline CA3 & 56 & $\overline{ \pm}$ & 6 & 64 & \pm & 7 & 14 & 63 & $\overline{ \pm}$ & $6^{\#}$ & 80 & \pm & $6^{\#}$ & 27 \\
\hline Raphé & & & & & & & & & & & & & & \\
\hline Dorsal & 90 & \pm & 9 & 107 & \pm & 11 & 19 & 74 & \pm & 7 & 97 & \pm & 4 & 32 \\
\hline Median & 60 & \pm & 8 & 84 & \pm & 8 & 40 & 59 & \pm & 4 & 81 & \pm & 7 & 38 \\
\hline Paramedian & 47 & \pm & 9 & 58 & \pm & 8 & 23 & 53 & \pm & 5 & 56 & \pm & 4 & 6 \\
\hline Mesocorticolimbic system & & & & & & & & & & & & & & \\
\hline Ventral tegmental area & 30 & \pm & 5 & 53 & \pm & $7 \star$ & 79 & 53 & \pm & $5^{\#}$ & 69 & \pm & $9^{\#, \star}$ & 30 \\
\hline Nucleus accumbens & 57 & \pm & 4 & 70 & \pm & 3 & 23 & 71 & \pm & 5 & 73 & \pm & 7 & 3 \\
\hline Multimodal & & & & & & & & & & & & & & \\
\hline Septal nucleus & 77 & \pm & 8 & 84 & \pm & 6 & 8 & 68 & \pm & 5 & 101 & \pm & $5^{\star},+$ & 48 \\
\hline Bed nucleus of the stria terminalis & 55 & \pm & 5 & 71 & \pm & 9 & 28 & 82 & \pm & $6^{\#}$ & 94 & \pm & $11^{\#}$ & 15 \\
\hline Lateral habenula & 52 & \pm & 8 & 61 & \pm & 6 & 18 & 63 & \pm & 5 & 45 & \pm & 8 & -28 \\
\hline Periaqueductal gray & 68 & \pm & 8 & 78 & \pm & 7 & 13 & 76 & \pm & 12 & 93 & \pm & 8 & 22 \\
\hline
\end{tabular}

${ }^{\dagger}$ Effect of $h$ SERT overexpression on $\left[{ }^{3} \mathrm{H}\right]$ paroxetine binding (fmol/mg tissue) in the central nervous system. Data are expressed as mean \pm SEM and percentage change in hSERT OVR mice compared with wild-type animals of the same sex. Data were analyzed by two-way ANOVA.

${ }^{\#} P<0.05$ sex difference.

${ }^{\star} P<0.05$, significant genotype effect (within sex with Bonferroni correction).

${ }^{+} P<0.05$ significant sex $\times$ genotype interaction. 


\section{Constitutive iLCMRglu}

In all brain regions, iLCMRglu tended to be lower in females than in males, and this was confirmed by the significant sex effect observed in 33 of the 46 brain regions analyzed. The most marked difference between the sexes was present in the anterior hypothalamus (mean 40\% lower in females). iLCMRglu was significantly lower in females compared with males in all hippocampal subregions (minimum effect $-14 \%$, maximum effect $-26 \%$ ) as well as in all amygdala (minimum $-23 \%$, maximum $-26 \%$ ) and raphé (minimum $-21 \%$, maximum $-26 \%$ ) nuclei.

In males, there was no evidence for a significant effect of hSERT OVR on iLCMRglu in any RoI. In contrast, in females, $h$ SERT overexpression produced a significant reduction in iLCMRglu in 34 of the 47 brain regions analyzed. In females, significant decreases in iLCMRglu were found in all cortical regions (range, $-31 \%$ in piriform cortex to $-44 \%$ in frontal cortex), raphé nuclei $(-36 / 37 \%)$, amygdala nuclei (range, $-30 \%$ in central to $-36 \%$ in basolateral), and in multiple hippocampal subfields (range, $-34 \%$ in dorsal subiculum to $-38 \%$ in the dorsal CA1) (Table II). This suggested that the ability of hSERT OVR to modify constitutive LCMRglu was influenced by sex. Indeed, the effect of hSERT OVR on the global level of cerebral metabolism was significantly greater in females than in males (MannWhitney U-test). Furthermore, when looking at each brain $\mathrm{RoI}$ independently a significant sex $\times$ genotype interaction was detected in 7 of the 46 brain regions analyzed (Fig. 3). These were detected in the medial striatum (26\% greater reduction in females; $F_{1,39}=4.34$, $P<0.05)$, globus pallidus $(25 \%$ greater reduction in females; $\left.F_{1,38}=4.39, P<0.05\right)$, ventrolateral thalamus $\left(32 \%\right.$ greater reduction in females; $F_{1,39}=5.52, P<$ $0.05)$, and the mammillary body (27\% greater reduction in females; $\left.F_{1,32}=5.86, P<0.05\right)$.

The terminal plasma ${ }^{14} \mathrm{C}$ and glucose concentrations for hSERT OVR and wild-type mice involved in the iLCMRglu study are shown in Table III. There was no evidence for a significant difference in these plasma variables between hSERT OVR and wild-type mice in either sex. Significant sex differences in terminal plasma glucose and ${ }^{{ }^{4}} \mathrm{C}$ levels, the former of which are at the lower end of the normal physiological range as a result of the overnight food restriction implemented in these studies, most likely results from the lower body weight of females compared with males. These differences result in a significant and appropriate sex-based adjustment of the plasma $\left[{ }^{14} \mathrm{C}\right]$ :[glucose] ratio for use in the determination of iLCMRglu and so differences in these plasma variables are unlikely to contribute to the sex differences in iLCMRglu found in this study.

\section{DISCUSSION}

Given the known influence of sex in affective disorders and reported sex differences in serotonergic system function (for review, see Rubinow et al., 1998), there is a paucity of data on sex differences in SERT expression. However, there is evidence that the density of highaffinity $\left[{ }^{3} \mathrm{H}\right]$ imipramine binding sites is greater in the brain of female rats (Ieni et al., 1985) and that $\beta$-CIT (2-beta-carboxymethoxy-3beta-(4-iodiphenyl)tropane), which labels both SERT and the dopamine transporter (DAT), is higher in human females than males (Staley et al., 2001). This provides some indirect support for our data showing significantly higher $\left[{ }^{3} \mathrm{H}\right]$ paroxetine binding to SERT in a number of diverse brain regions in female mice when compared with males. Although the sex steroids may have a role in determining observed sex differences in SERT protein expression, the exact relationship may not be simple. Thus, although exogenous estrogen has been found to stimulate both SERT gene transcription and protein expression levels (McQueen et al., 1997), the effects are highly localized in the brain, and the pattern does not match the regional distribution of sex differences found in naturally cycling mice in our study. Furthermore, testosterone in males has been found to stimulate SERT expression (McQueen et al., 1999) almost as much as estrogen does in females. Therefore, it seems unlikely that sex differences in SERT expression are determined solely by the acute regulatory effects of the sex steroids. Whatever the mechanism, sex differences in SERT protein expression and function are likely to contribute to some of the sexual dimorphisms reported in functions associated with the 5-HT system, including sex differences in affective function and antidepressant efficacy. In particular, the enhanced expression of SERT in females may prove to be central to the decreased levels of synaptic 5-HT found in females compared with males (Gundlah et al., 1998; Jones and Lucki, 2005; Mitsushima et al., 2006).

Applying the same radioligand imaging that we used in wild-type mice, we found that although $\left[{ }^{3} \mathrm{H}\right]$ paroxetine binding was increased in hSERT OVR mice, the regional distribution of binding was qualitatively similar to that found in wild-type mice, as reported previously (Jennings et al., 2006). Furthermore, the pattern was essentially similar to that described using a variety of selective SERT radioligands in rats (DeSouza and Kuyatt, 1987; Reader et al., 1998; Sharkey et al., 1991). The expression of both murine and human SERT proteins in hSERT OVR mice results in the presence of more than one pharmacologically defined binding site for SERT ligands (Loder et al., 2000), presumably as a result of the differing affinities of murine compared with the human transporter for these ligands (Plenge and Mellerup, 1991). However, the use of a saturating concentration of radioligand in our studies for both species of SERT proteins allows us to suggest that it is increased SERT protein expression $\left(B_{\max }\right)$ rather than altered affinity that accounts for the increased $\left.{ }^{3} \mathrm{H}\right]$ paroxetine binding found in hSERT OVR mice. Interestingly, we also found that the reported enhancement of SERT gene transcription, as reflected by the increase in SERT mRNA observed in the raphe nuclei of hSERT OVR mice (Jennings et al., 2006), does not result in a universal increase in SERT protein expression 
TABLE II. Constitutive iLCMRglu in $h$ SERT OVR and Wild-type Mice ${ }^{\dagger}$

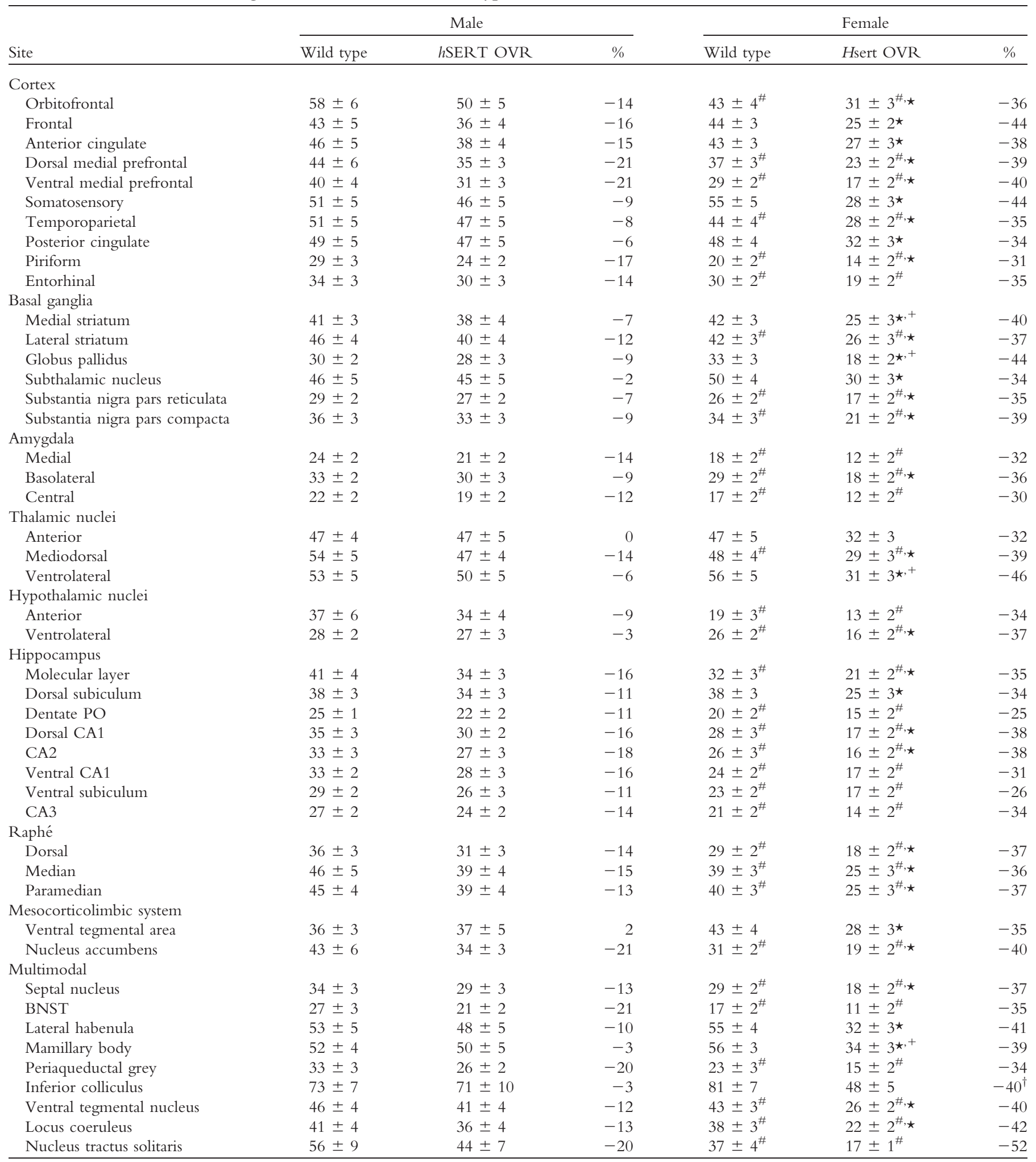

${ }^{\dagger}$ Constitutive iLCMRglu $\left(\mathrm{nCi} \cdot \mathrm{mg}^{-1} / \mathrm{nCi} \mu \mathrm{mol}^{-1}\right)$ in male and female $h$ SERT OVR and wild-type mice. Data shown as mean \pm SEM iLCMRglu and $\%$ change in $h$ SERT OVR mice compared with wild-type animals of the same sex. Data were analyzed by two-way ANOVA.

${ }^{\#} P<0.05$ significant sex effect.

$\star P<0.05$ significant $h$ SERT effect within sex (two-way ANOVA with Bonferroni correction).

${ }^{+} P<0.05$ significant sex $\times$ genotype interaction. 
(A)

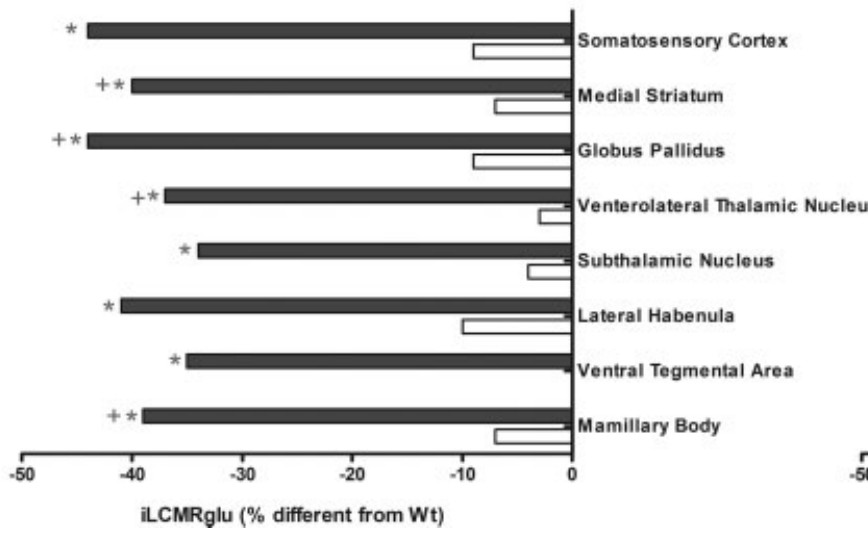

(B)

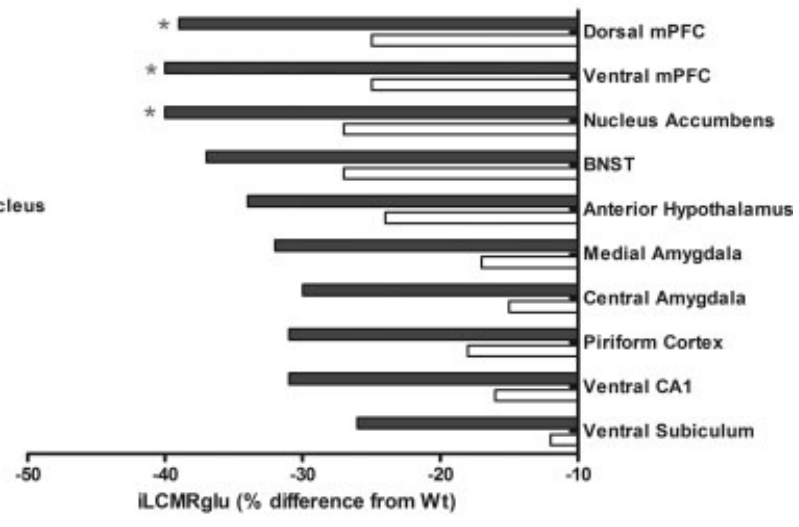

Fig. 3. Effect of hSERT OVR on constitutive iLCMRglu in male and female mice. Data shown as percentage difference in the iLCMRglu from appropriate wild-type control. Representative regions are shown for the $(\mathbf{A})$ maximum and $(\mathbf{B})$ minimum sex difference in the effect of $h \mathrm{SERT}$ overexpression on iLCMRglu. ${ }^{\star} P<0.05$ significant $h$ SERT effect (within-sex Bonferroni correction). ${ }^{+} P<0.05$ significant sex $\times$ hSERT OVR interaction (two-way ANOVA).

TABLE III. Plasma Glucose and ${ }^{14} \mathrm{C}$ in $h$ SERT OVR and Wild-type Mice ${ }^{\dagger}$

\begin{tabular}{lrrrrr}
\hline & \multicolumn{2}{c}{ Male } & & \multicolumn{2}{c}{ Female } \\
\cline { 2 - 4 } Variable & \multicolumn{1}{c}{ Wild type } & hSERT OVR & & Wild type & $h$ SERT OVR \\
\hline Plasma glucose $\left(\mu \mathrm{mol} \cdot \mathrm{ml}^{-1}\right)$ & $9.03 \pm 0.61$ & $7.28 \pm 0.80$ & & $6.52 \pm 0.44^{\star}$ & $7.68 \pm 0.49$ \\
Plasma $\left[{ }^{14} \mathrm{C}\right]\left(\mathrm{nCi} \cdot \mathrm{ml}^{-1}\right)$ & $77.47 \pm 4.53$ & $75.69 \pm 8.55$ & & $96.05 \pm 13.57 \star$ & $138.48 \pm 18.12^{\star}$ \\
Plasma $\left[{ }^{14} \mathrm{C}\right]:[\mathrm{glucose}]\left(\mathrm{nCi} \cdot \mu \mathrm{mol}^{-1}\right)$ & $8.41 \pm 0.65$ & $11.89 \pm 1.95$ & & $15.34 \pm 2.11^{\star}$ & $18.02 \pm 2.41^{\star}$ \\
\hline
\end{tabular}

${ }^{\dagger}$ Terminal plasma ${ }^{14} \mathrm{C}\left(\mathrm{nCi} \cdot \mathrm{ml}^{-1}\right)$ and glucose $\left(\mu \mathrm{mol} \cdot \mathrm{ml}^{-1}\right)$ concentrations in wild-type and $h \mathrm{SERT}$ OVR mice. Data are mean $\pm \mathrm{SEM}$.

$\star P<0.05$ significant sex difference (within genotype; Student's $t$-test with Bonferroni correction).

throughout the brain. Rather, SERT expression is enhanced in a regionally heterogenous manner, with the greatest increase found in anterior cortical regions, moderate increases in components of the basal ganglia, hippocampal regions, and raphé, while in other regions, such as the amygdala nuclei, no increase is observed. This suggests that the increased SERT protein expression in hSERT OVR mice is not directly related to the enhancement of SERT gene transcription. Rather, complicated regulatory mechanisms must exist that govern SERT protein expression levels, and these must operate in a brain region-specific manner. As yet, the nature of these mechanisms is not understood, but because they will directly regulate the outcome of enhanced SERT gene transcription, they are likely to be central in mediating altered serotonergic function in hSERT OVR mice. The same mechanisms may also mediate the effects of the 5-HTTLPR polymorphism on brain and affective functioning in humans.

The approximate 2-fold increase in SERT binding, in specific brain regions of $h$ SERT OVR mice, shows a striking parallel to the magnitude of increase (also approximately 2 -fold) in SERT binding, mRNA expres- sion, and 5-HT reuptake found in both brain and blood platelets of human individuals with the $1 / 1$ genotype over those of the s/l or s/s genotype (Greenberg et al., 1999; Heinz et al., 2000; Little et al., 1998). This adds further credence to the suggestion that hSERT OVR mice provide a useful model of the natural variation in SERT protein expression observed in humans-for example, as a result of the 5-HTTLPR polymorphism. However, it is also important to note that a number of other studies have reported that there is no effect of the 5-HTTLPR polymorphism on SERT binding in the human brain (Parsey et al., 2006; Shioe et al., 2003; Van Dyck et al., 2004; Willeit et al., 2001). Although it is interesting to speculate, with reference to our results, that the regional localization of the binding measurements made in some of these studies may be responsible for their negative findings, it is also likely that the use of small sample sizes in some of these studies might contribute to their negative results. More importantly, because our results suggest that the ability of a genetically determined increase in SERT transcription increases SERT protein expression is strongly influenced by sex, with greater increases occurring in females than in males, lack of sample segre- 
gation on the basis of sex in human studies investigating the 5-HTTLPR polymorphism may be a major confounding factor resulting in their negative results.

In this study, we found that a lifelong increase in SERT function decreases constitutive cerebral metabolism in a number of brain regions, and that this effect was only significant in females. Interestingly, many of the regions in which a decreased rate of iLCMRglu was found in hSERT OVR females compared with wildtype animals are strongly implicated in the regulation of anxiety. Pharmacological challenges associated with an anxiolytic effect, including acute diazepam and phenobarbital treatment, commonly result in decreased LCMRglu in many of the regions in which constitutive iLCMRglu is decreased in hSERT OVR mice. These regions include the mamillary body, ventrolateral thalamus, septal nucleus, medial striatum, and globus pallidus (Ableitner et al., 1985; Ableitner and Herz, 1987; Kelly et al., 1986). In addition, a number of anxiogenic pharmacological challenges have been reported to elicit increased LCMRglu in these structures (Pratt et al., 1988; Ableitner and Herz, 1987) and chronic prenatal treatment with diazepam, which produces an anxiolyticlike phenotype in the "drug-free" adult, is also associated with reduced LCMRglu in many of these brain regions (Schroeder et al., 1997).

Our data suggest that constitutive cerebral function is decreased in several brain structures in which neuronal activity is positively correlated with anxiety. In addition, elevated LCMRglu in the lateral habenula appears to be the most robust correlate of depressive behavior in rats, and this hypermetabolism is reversed, in parallel with the alleviation of depressive-like behavior, by antidepressant treatment (Caldecott-Hazard et al., 1988). In this context, it is worth noting that iLCMRglu is also significantly decreased in the lateral habenula of hSERT OVR mice, suggesting that hypometabolism in this region may contribute to their depression-resistant phenotype. In a wider context, the observation of decreased constitutive metabolism in limbic structures of female hSERT OVR mice parallels the reported basal frontolimbic hypometabolism reported in 1/1 compared with s/s allele human individuals (Graff-Guerrero et al., 2005). However, in contrast to the observation that hypometabolism is limited to frontal cortical structures in $1 / 1$ human individuals, we found evidence for a more widespread effect in hSERT OVR female mice, which also included many subcortical regions and the raphé nuclei. One reason for this disparity may be the lack of sample segregation on the basis of sex in the human study, which could lead to the masking of a more widespread hypometabolism in $1 / 1$ allele females by the presence of a smaller effect in males.

Evidence from both $\left[{ }^{3} \mathrm{H}\right]$ paroxetine binding and constitutive iLCMRglu data suggests that sex modulates the influence of a lifelong increase in SERT transcription on these parameters, with a greater effect in females than in males. The greater increase in $\left[{ }^{3} \mathrm{H}\right]$ paroxetine binding induced by hSERT overexpression in females compared with males suggests that direct sex modulation of the increase in SERT protein expression elicited in response to increased SERT gene transcription may be central to the sex-dependent effects of the 5-HTTLPR polymorphism on affective functioning. However, in hSERT OVR mice the modulatory influence of sex on increased SERT expression was limited in its regional distribution, being significant in the dorsal subiculum and septal nucleus. In contrast, the influence of sex on the cerebral hypometabolism present in hSERT OVR animals was more widespread and did not include either the dorsal subiculum or septum. Furthermore, the regions in which iLCMRglu was altered by hSERT OVR to a greater extent in females than in males do not receive dense innervation from either the dorsal subiculum or septum. Thus, in terms of anatomical distribution, the effect of sex on the ability of hSERT overexpression to induce cerebral hypometabolism does not directly map onto the effect of sex on the altered SERT expression levels in these animals. However, it is commonly reported that regional alterations in LCMRglu in response to pharmacological challenge do not correlate with the regional distribution of receptors. This is thought to be due to both the sensitivity of the method, which localizes metabolic alterations at the synapse rather than cell body and to the convergence and contribution of polysynaptic pathways to the observed alterations in LCMRglu. Therefore, it is not surprising that the sex effects of $h$ SERT OVR on SERT protein expression show little spatial correlation with those of iLCMRglu. Furthermore, sex-dependent modulation of any alteration in 5-HT receptor functioning that may occur in response to the altered SERT function present in hSERT OVR animals may also contribute to the differences noted in iLCMRglu. Such a mechanism has been found to exist in SERT KO mice where alteration in 5$\mathrm{HT}_{1 \mathrm{~A}}$ receptor function are found in female, but not male, animals (Li et al., 2000).

Overall, these data suggest that a lifelong increase in SERT transcription modifies constitutive cerebral function to a greater extent in females than in males. Although this finding parallels reported sex differences observed in humans in the effect of the 5-HTTLPR polymorphism on affective functioning, the possible sex difference in anxiety-like behavior in hSERT OVR animals has not been investigated. However, our data suggest that hSERT overexpression may produce a greater anxiolytic effect in females than in males. In summary, alterations in SERT expression and cerebral function in hSERT OVR mice parallel those observed in 1/1 allele human individuals, suggesting that hSERT OVR mice provide a useful animal model of the 5-HTTLPR polymorphism. In addition, these alterations are greater in females than in males, which parallels the known sex difference in the effect of the 5-HTTLPR polymorphism on affective functioning in humans.

\section{ACKNOWLEDGMENT}

Neil Dawson was funded by an MRC studentship. 


\section{REFERENCES}

Ableitner A, Herz A. 1987. Influence of meprobamate and phenobarbital upon local cerebral glucose utilization-parallelism with effects of the anxiolytic diazepam. Brain Res 403:82-88.

Ableitner A, Wuster M, Herz A. 1985. Specific changes in local cerebral glucose utilization in the rat brain induced by acute and chronic diazepam. Brain Res 359:49-56.

Ball D, Hill L, Freeman B, Eley TC, Strelau J, Riemann R, Spinath FM, Angleitner A, Plomin R. 1997. The serotonin transporter gene and peer-rated neuroticism. Neuroreport 8:1301-1304.

Brummett BH, Boyle SH, Siegler IC, Kuhn CM, Ashley-Koch A, Jonassaint CR, Zuchner S, Collins A, Williams RB. 2008. Effects of environmental stress and gender on associations among symptoms of depression and the serotonin transporter gene linked polymorphic region (5HTTLPR). Behav Genet 38:34-43.

Caldecott-Hazard S, Mazziotta J, Phelps M. 1988. Cerebral correlates of depressed behavior in rats, visualized using ${ }^{14} \mathrm{C}-2$-deoxyglucose autoradiography. J Neurosci 8:1951-1961.

Caspi A, Sugden K, Moffitt TE, Taylor A, Craig IW, Harrington H, McClay J, Mill J, Martin J, Braithwaite A, Poulton R. 2003. Influence of life stress on depression: moderation by a polymorphism in the 5HTT gene. Science 301(5631):386-389.

Dawson N, Ferrington L, Olverman HJ, Kelly PAT. 2008. Novel analysis for improved validity in semi-quantitative 2-deoxyglucose autoradiography. J Neurosci Methods 175:25-35.

DeSouza EB, Kuyatt BL. 1987. Autoradiographic localization of ${ }^{3} \mathrm{H}-$ paroxetine-labeled serotonin uptake sites in rat brain. Synapse 1:488496.

Du LS, Bakish D, Hrdina PD. 2000. Gender differences in association between serotonin transporter gene polymorphism and personality traits. Psychiatr Genet 10:159-164.

Franklin KBJ, Paxinos G. 1997. The mouse brain in stereotaxic co-ordinates: Academic Press, New York.

Furlong RA, Ho L, Walsh C, Rubinsztein JS, Jain S, Paykel ES, Easton DF, Rubinsztein DC. 1998. Analysis and meta-analysis of two serotonin transporter gene polymorphisms in bipolar and unipolar affective disorders. Am J Med Genet 81:58-63.

Gelernter J, Kranzler H, Coccaro EF, Siever LJ, New AS. 1998. Serotonin transporter protein gene polymorphism and personality measures in African American and European American subjects. Am J Psychiat 155:1332-1338.

Grabe HJ, Lange M, Wolff B, Volzke H, Lucht M, Freyberger HJ, John U, Cascorbi I. 2005. Mental and physical distress is modulated by a polymorphism in the 5-HT transporter gene interacting with social stressors and chronic disease burden. Mol Psychiatry 10:220-224.

Graff-Guerrero A, De la Fuente-Sandoval C, Camarena B, Gomez-Martin D, Apiquian R, Fresan A, Aguilar A, Mendez-Nunez JC, EscalonaHuerta C, Drucker-Colin R, Nicolini H. 2005. Frontal and limbic metabolic differences in subjects selected according to genetic variation of the SLC6A4 gene polymorphism. Neuroimage 25:1197-1204.

Greenberg BD, Tolliver TJ, Huang SJ, Li Q, Bengel D, Murphy DL. 1999. Genetic variation in the serotonin transporter promoter region affects serotonin uptake in human blood platelets. Am J Med Genet 88:83-87.

Greenberg B, Li Q, Lucas F, Hu S, Sirota L, Benjamin J, Lesch K, Hamer D, Murphy D. 2000. Association between the serotonin transporter promoter polymorphism and personality traits in a primarily female population sample. Am J Med Genet 96:202-216.

Gundlah C, Simon LD, Auerbach SB. 1998. Differences in hypothalamic serotonin between estrous phases and gender: an in vivo microdialysis study. Brain Res 785:91-96.

Hanna GL, Himle JA, Curtis GC, Koram DQ, Weele JVV, Leventhal BL, Cook EH. 1998. Serotonin transporter and seasonal variation in blood serotonin in families with obsessive-compulsive disorder. Neuropsychopharmacology 18:102-111.

Heinz A, Jones DW, Mazzanti C, Goldman D, Ragan P, Hommer D, Linnoila M, Weinberger DR. 2000. A relationship between serotonin transporter genotype and in vivo protein expression and alcohol neurotoxicity. Biol Psychiatry 47:643-649.

Holmes A, Yang RJ, Lesch KP, Crawley JN, Murphy DL. 2003. Mice lacking the serotonin transporter exhibit 5-HT1A receptor-mediated abnormalities in tests for anxiety-like behavior. Neuropsychopharmacology 28:2077-2088.

Ieni JR, Tobach E, Zukin SR, Barr GA, Vanpraag HM. 1985. Multiple $\left[{ }^{3} \mathrm{H}\right]$ imipramine binding sites in brains of male and female fawn-hooded and long-evans rats. Eur J Pharmacol 112:261-264.

Jennings K, Sheward J, Harmar A, Sharp T. 2003. Mice over-expressing the 5-HT transporter show evidence of increased central 5- $\mathrm{HT}_{2 \mathrm{~A}}$ function. Br J Pharmacol 138:U88-U88.

Jennings KA, Loder MK, Sheward WJ, Pei Q, Deacon RMJ, Benson MA, Olverman HJ, Hastie ND, Harmar AJ, Shen SB, Sharp T. 2006. Increased expression of the 5-HT transporter confers a low-anxiety phenotype linked to decreased 5-HT transmission. J Neurosci 26:89558964.

Jones MD, Lucki I. 2005. Sex differences in the regulation of serotonergic transmission and behavior in 5-HT receptor knockout mice. Neuropsychopharmacology 30:1039-1047.

Kelly PAT, Ford I, McCulloch J. 1986. The effect of diazepam upon local cerebral glucose use in the conscious rat. Neuroscience 19:257265.

Kim DK, Tolliver TJ, Huang SJ, Martin BJ, Andrews AM, Wichems C, Holmes A, Lesch KP, Murphy DL. 2005. Altered serotonin synthesis, turnover and dynamic regulation in multiple brain regions of mice lacking the serotonin transporter. Neuropharmacology 49:798-810.

Lesch K, Bengel D, Heils A, Sabol S, Greenberg B, Petri S, Benjamin J, Muller C, Hamer D, Murphy D. 1996. Association of anxiety-related traits with a polymorphism in the serotonin transporter gene regulatory region. Science 274(5292):1527-1531.

Li Q, Wichems C, Heils A, Lesch KP, Murphy DL. 2000. Reduction in the density and expression, but not G-protein coupling, of serotonin receptors $\left(5-\mathrm{HT}_{1 \mathrm{~A}}\right)$ in $5-\mathrm{HT}$ transporter knock-out mice: gender and brain region differences. J Neurosci 20:7888-7895.

Little KY, McLaughlin DP, Zhang L, Livermore CS, Dalack GW, McFinton PR, DelProposto ZS, Hill E, Cassin BJ, Watson SJ, Cook EH. 1998. Cocaine, ethanol, and genotype effects on human midbrain serotonin transporter binding sites and mRNA levels. Am J Psychiat 155:207-213.

Loder M, Shen S, Wren P, Sharp T, Olverman H, Harmar A. 2000. The production and analysis of transgenic mice expressing the human serotonin transporter. Eur J Neurosci 12:173-173.

Lotrich FE, Pollock BG. 2004. Meta-analysis of serotonin transporter polymorphisms and affective disorders. Psychiatr Genet 14:121-129.

Mann JJ, Huang JY, Underwood MD, Kassir SA, Oppenheim S, Kelly TM, Dwork AJ, Arango V. 2000. A serotonin transporter gene promoter polymorphism (5-HTTLPR) and prefrontal cortical finding in major depression and suicide. Arch Gen Psychiatry 57:729-738.

McCulloch J, Kelly PAT, Ford I. 1982. Effect of apomorphine on the relationship between local cerebral glucose utilization and local cerebral blood flow (with an appendix on its statistical analysis). J Cereb Blood Flow Metab 2:487-499.

McQueen JK, Wilson H, Fink G. 1997. Estradiol-17 beta increases serotonin transporter (SERT) mRNA levels and the density of SERT-binding sites in female rat brain. Mol Brain Res 45:13-23.

McQueen JK, Wilson H, Sumner BEH, Fink G. 1999. Serotonin transporter (SERT) mRNA and binding site densities in male rat brain affected by sex steroids. Mol Brain Res 63:241-247. 
Mitsushima D, Yamada K, Takase K, Funabashi T, Kimura F. 2006. Sex differences in the basolateral amygdala: the extracellular levels of serotonin and dopamine, and their responses to restraint stress in rats. Eur J Neurosci 24:3245-3254.

Mizuno T, Aoki M, Shimada Y, Inoue M, Nakaya K, Takahashi T, Itoyama Y, Kanazawa M, Utsumi A, Endo Y, Nomura T, Hiratsuka M, Mizugaki M, Goto J, Hongo M, Fukudo S. 2006. Gender difference in association between polymorphism of serotonin transporter gene regulatory region and anxiety. J Psychosom Res 60:91-97.

Parsey RV, Hastings RS, Oquendo MA, Hu XZ, Goldman D, Huang YY, Simpson N, Arcement J, Huang YY, Ogden RT, Van Heertum RL, Arango V, Mann JJ. 2006. Effect of a triallelic functional polymorphism of the serotonin-transporter-linked promoter region on expression of serotonin transporter in the human brain. Am J Psychiat 163:48-51.

Plenge P, Mellerup ET. 1991. [ $\left.{ }^{3} \mathrm{H}\right]$ Citalopram binding to brain and platelet membranes of human and rat. J Neurochem 56:248-252.

Pratt JA, Laurie DJ, McCulloch J. 1988. The Effects of Fg-7142 upon local cerebral glucose utilization suggest overlap between limbic structures important in anxiety and convulsions. Brain Res 475:218-231.

Reader TA, Le Marec N, Hebert C, Amdiss F, Botez MI. 1998. Distribution of serotonin transporters in the central nervous system of wild type and Purkinje cell degeneration mutant mice. J Neurochem 70:S69-S69.

Rubinow DR, Schmidt PJ, Roca CA. 1998. Estrogen-serotonin interactions: implications for affective regulation. Biol Psychiatry 44:839-850.

Schinka JA, Busch RM, Robichaux-Keene N. 2004. A meta-analysis of the association between the serotonin transporter gene polymorphism (5-HTTLPR) and trait anxiety. Mol Psychiatry 9:197-202.

Schroeder H, Humbert AC, Desor D, Nehlig A. 1997. Long-term consequences of neonatal exposure to diazepam on cerebral glucose utilization, learning, memory and anxiety. Brain Res 766:142-152.
Sharkey J, Mcbean DE, Kelly PAT. 1991. Alterations in hippocampal function following repeated exposure to the amphetamine derivative methylenedioxymethamphetamine (ecstasy). Psychopharmacology 105: 113-118.

Shioe K, Ichimya T, Suhara T, Takano A, Sudo Y, Yasuno F, Hirano M, Shinohara M, Kagami A, Okubo Y, Nankai M, Kanba S. 2003. No association between genotype of the promoter region of serotonin transporter gene and serotonin transporter binding in human brain measured by PET. Synapse 48:184-188.

Sjoberg RL, Nilsson KW, Nordquist N, Ohrvik J, Leppert J, Lindstrom L, Oreland L. 2006. Development of depression: sex and the interaction between environment and a promoter polymorphism of the serotonin transporter gene. Int J Neuropsychopharmacol 9:443-449.

Sokoloff L, Reivich M, Kennedy C, Desrosiers M, Patlak C, Pettigrew K, Sakurada O, Shinohara M. 1977. ${ }^{14} \mathrm{C}$-2-deoxyglucose method for measurement of local cerebral glucose-utilization-theory, procedure, and normal values in conscious and anesthetized albino-rat. J Neurochem 28:897-916.

Staley JK, Krishnan-Sarin S, Zoghbi S, Tamagnan G, Fujita M, Seibyl JP, Maciejewski PK, O'Malley S, Innis RB. 2001. Sex differences in $\left[{ }^{123} \mathrm{I}\right]$ beta-CIT SPECT measures of dopamine and serotonin transporter availability in healthy smokers and nonsmokers. Synapse 41:275-284.

Van Dyck CH, Malison RT, Staley JK, Jacobsen LK, Seibyl JP, Laruelle M, Baldwin RM, Innis RB, Gelernter J. 2004. Central serotonin transporter availability measured with $\left[{ }^{123} \mathrm{I}\right]$ beta-CIT SPECT in relation to serotonin transporter genotype. Am J Psychiatry 161:525-531.

Willeit M, Stastny J, Pirker W, Praschak-Rieder N, Neumeister A, Asenbaum S, Tauscher J, Fuchs K, Sieghart W, Hornik K, Aschauer HN, Brucke T, Kasper S. 2001. No evidence for in vivo regulation of midbrain serotonin transporter availability by serotonin transporter promoter gene polymorphism. Biol Psychiatry 50:8-12. 